DOI: $10.14451 / 1.171 .153$

\title{
АНАЛИЗ ФУНКЦИОНИРОВАНИЯ ПРЕДСТАВИТЕЛЬСТВ ИНОСТРАННЫХ КОМПАНИЙ НА РЫНКЕ ТАКСИ В РОССИИ
}

\author{
(C) 2019 Петров Александр Михайлович \\ доктор экономических наук, профессор Департамента учета, анализа и аудита \\ Финансовый университет при Правительстве Российской Федерации \\ 125993, г. Москва, Ленинградский пр-т, д.49 \\ E-mail: palmi@inbox.ru \\ (C) 2019 Бурцева Ксения Юрьевна \\ кандидат экономических наук, доцент Департамента учета, анализа и аудита \\ Финансовый университет при Правительстве Российской Федерации \\ 125993, г. Москва, Ленинградский пр-т, д. 49 \\ E-mail: aksentiya@mail.ru \\ (C) 2019 Королев Алексей Алексеевич \\ аспирант Департамента учета, анализа и аудита \\ Финансовый университет при Правительстве Российской Федерации \\ 125993, г. Москва, Ленинградский пр-т, д. 49 \\ E-mail: korolev_alexey@mail.ru
}

В условиях процессов глобализации в экономических системах государств наблюдается всестороннее проникновение международных компаний, применяющих глобальные бизнес-модели на региональных рынках. Совсем недавно на рынке пассажирских перевозок России наблюдалось абсолютное доминирование нелегального сектора, что сменилось значительной динамикой роста рынка и трансформацией организации его функционирования ввиду стремительного проникновения современных глобальных технологий. Одной из доминирующих на российском рынке стала международная компания «Gett», ставшая предметом исследования в целях анализа рынка такси и особенностей функционирования международных представительств зарубежных компаний на территории России.

Ключевые слова: рынок такси, пассажирские перевозки, иностранные представительства, стратегия, бизнес-модель.

В недавнем времени на российском рынке такси наблюдалось доминирование нелегальных пассажирских перевозок. На текущий момент рынок является динамично развивающимся и по оценкам Аналитического центра при Правительстве Российской Федерации достиг уровня свыше 575 млрд. рублей в 2017 году. При растущем объеме наблюдается и значительная трансформация в организации рынка из-за проникновения глобальных бизнес-моделей. Одним из ключевых игроков на рынке такси в России является представительство международной компании «Gett».

Компания «Gett» была основана в 2011 в Израиле, представлена в России, США, Израиле и Великобритании [1]. На территории нашей страны представительство компании «Gett» существует в форме ООО «ГЕТТАКСИ РУС», зарегистрированной также в 2011 году. Конечной головной компанией, владеющий российским представительством является кипрская «GT GETTAXI LIMITED» [2]. В настоящий момент российское представительство компании представлено более, чем в 75 городах, включая все города миллионеры [1].

Анализ функционирования иностранных представительств целесообразно проводить с использованием методического инструментария, принятого для проведения бизнес-анализа Ассоциацией присяжных сертифицированных бухгалтеров (ACСА) [3], начав с ключевых характеристик рынка такси, перейдя к анализу состояния отрасли в России и затем приступить конкурентному анализу компании «Gett».

Трансформация рынка такси привела к тому, что на текущий момент на рынке, в том числе и российском, сосуществуют несколько основных бизнес-моделей: 
- Таксопарки. Данный сегмент является по большей части пережитком старой бизнес-модели работы такси ввиду ряда причин. Во-первых, в эпоху повсеместной цифровизации многие таксопарки работают преимущественно через прием заказов посредствам телефонной связи. Во-вторых, характерной проблемой для таксопарков является нестабильность качества заказов, поскольку оценка качества работы сотрудников производится самой организацией. В-третьих, для крупных городов имеется проблема, связанная со скоростью подачи автомобиля, поскольку зачастую таксопарки имеют ограниченные возможности покрытия территории. При этом следует отметить, что наличие укомплектованного штата сотрудников и собственного парка автомобилей представляется возможным отнести к определенным преимуществам данной бизнес-модели, поскольку данные факторы могут создавать определенный уровень стабильности для бизнеса.

- Агрегаторы такси. Данная современная модель организации перевозки пассажиров характеризуется отсутствием собственного парка автомобилей и штата водителей. Вместо этого данные сервисы являются посредниками, осуществляя роль координаторов (маркетплейс) через мобильные приложения. Данную бизнес-модель используют, в частности, такие известные игроки как «Uber» и «Gett». В сравнении с таксопарками преимущества в покрытии территории и возможности быстрой подачи автомобиля стразу становятся очевидными. Также внешний контроль качества перевозок пассажирами позволяет отказаться от услуг непрофессиональных водителей.

- Каршеринг. Аренда ближайших свободных автомобилей через мобильное приложение в последнее время стало набирать большую популярность в столичном регионе в качестве альтернативы личному и общественному транспорту в связи с ценой аренды, которая ниже цены владения собственным автомобилем и повсеместным распространением платных автомобильных стоянок.

- Р2Р сервисы аренды автомобиля. Данные сервисы также выполняют роль координаторов при аренде автомобилей одними пользователями у других пользователей сервиса. Однако данная бизнес-модель не получила широкого распространения на территории России.

- Карпулинг сервисы. Отличительной характеристикой данной бизнес-модели является ориентированность на длительные поездки, поскольку даже использование каршеринга зачастую ограничено пределами региона. Пользователи с помощью данных сервисов посредствам приложений и других подобных средств могут находить попутчиков для организации совместных длительных междугородних переездов.

При использовании бизнес-модели агрегатора на рынке такси, ее эффективность принято оценивать по трем ключевым параметрам, представленных на рисунке 1.

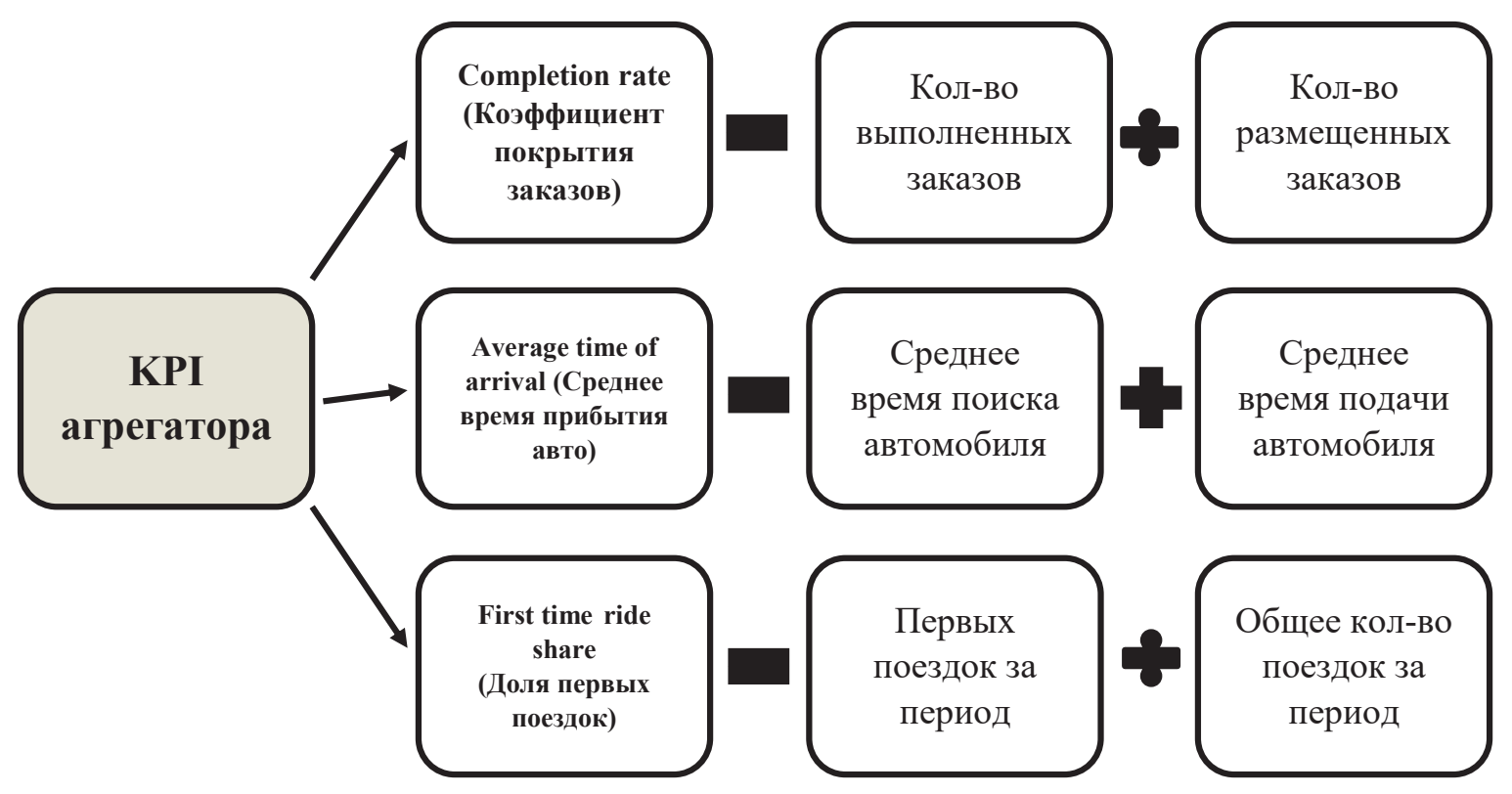

Puc. 1. Ключевые показатели (KРI) эффективности при оценке агрегаторов такси [4, с. 15] 
Ранее отмеченный растущий объем рынка такси в России целесообразно рассмотреть с точки зрения качественных параметров развития рынка. Проведем анализ на примере г. Москвы, поскольку данных региональный рынок является самым крупным в России и на нем представлена работа всех ранее описанных моделей пассажирских перевозок.

Ключевые качественные параметры, такие как средний чек поездки на такси и средняя стоимость 1 км поездки для московского региона, представлены на рисунке 2.

Рассматривая динамику показателей рынка такси в г. Москве, представляется возможным говорить о некоторых тенденциях, происходящих в сфере пассажирских перевозок. В частности, при относительно стабильной средней стоимости 1 км наблюдается устойчивая динамика к снижению размера среднего чека поездки на такси. При наблюдаемом росте объемов рынка это свидетельствует о том, что сокращается дальность поездки, и динамика роста рынка обеспечивается за счет увеличения количества поездок. Данные факторы не отражаются на клиентах в ценовом выражении, однако приводят к повышению конкуренции и росту расходов, связанных с подачей автомобиля и др., в абсолютном и относительном выражении, что, в свою очередь, в конечном итоге сказывается на всех игроках рынка, поскольку даже агрегаторы, не владеющие собственным автопарком, будут вынуждены снизить процент комиссии за услуги. Реакция рынка на данные обстоятельства часто выражается в трансформации стратегий и бизнес-моделей компаний.

По оценкам Аналитического центра при Правительстве Российской Федерации в 2017 году на долю агрегаторов такси приходилось 32,8\% общего объема рынка [5, с. 27]. Общее соотношение сил среди агрегаторов такси в России представлено на рисунке 3.

Основными конкурентами агрегатора такси «Gett» на московском рынке являются «Яндекс» и «Uber» (в настоящее время принадлежит «Яндекс»).

Стратегия «Яндекс» ориентирована во многом на экстенсивный рост и давление на предложение, о чем свидетельствует покупка конкурентов, в том числе «Uber», в различных смежных областях интересов фирмы. У «Яндекс» также имеются значительные возможности для повышения операционной эффективности, поскольку компания обладает собственной картографической, аналитической системы дорожной сети и навигационной системой [6]. Также компания обладает собственной платежной системой и обильными связями с российскими компаниями.

«Uber» является одним из мировых лидеров по технологиям онлайн-сервисов вызова такси и, в некоторой степени, законодателем применения смежных бизнес-моделей, в частности, «UberEats» по доставке еды из ресторанов и «UberPool», который позволяет осуществлять перевозку нескольких пассажиров [7].

Компания «Gett» формируя общую страте-

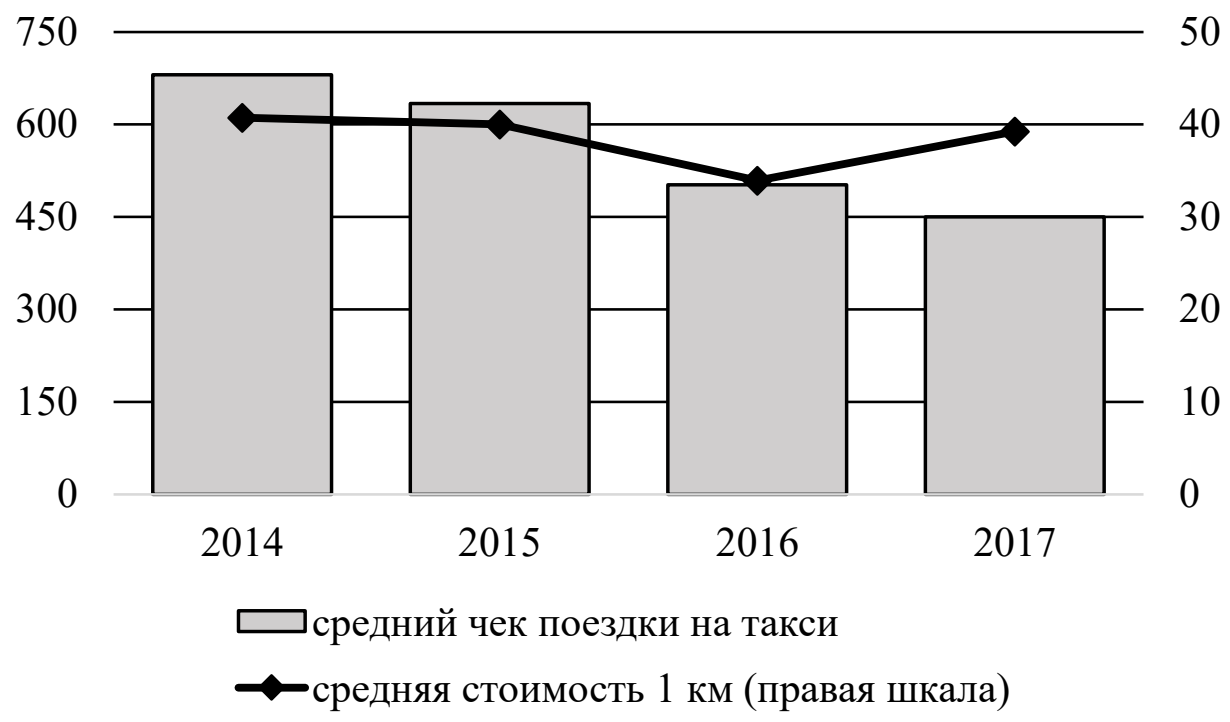

Puc. 2. Динамика размера среднего чека поездки на такси и средней стоимости 1 км в Москве, руб. [5, с. 12] 


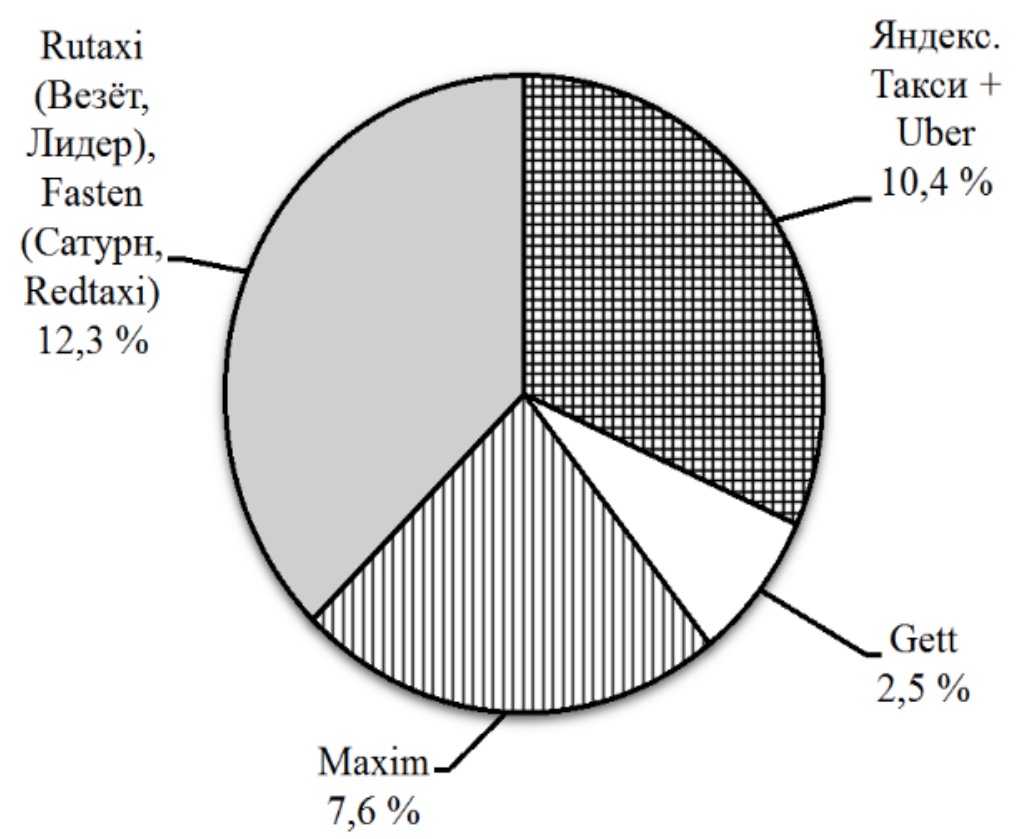

Puc. 3. Соотношение сил среди агрегаторов такси и их доли от общего объема рынка такси в России,\% [5, с. 27]

гию развития выделяет рынок такси Москвы как один из основных. В качестве основного направления стратегической работы на московском рынке определена борьба с конкурентами за предложение. Реализация целей будет проходить за счет повышения гибкости работы с водителями, их обучение, сопровождение и помощь в оформлении документов, работа с индивидуальными предпринимателями и др. Еще одним направлением развития на рынке Москвы является запуск и совершенствование сторонних сервисов. По примеру работы данной бизнес-модели в других регионах присутствия компании «Gett» («GettFlowers» по доставке цветов в Израиле, «GettSalad» по доставке салатов в Великобритании, «IMaster» по срочному ремонту экранов IPhone в России) будет осуществляться работа и в московском регионе. При этом подразумевается использование агрессивного маркетинга при продвижении компании.

Еще одним из стратегических направлений развития компании «Gett» является укрепление позиций в регионах присутствия путем привлечения местных таксопарков и ценовая борьба с таксопарками-конкурентами путем субсидирования региональных отделений компании «Gett».

Третьим стратегическим направлением развития является завоевание рынка в новых городах с помощью использования агрессивного маркетинга, демпинговых цен на услуги такси и выгодных предложений для развития сети партнерских таксопарков.

При этом следует обратить внимание на развитие сторонних сервисов компании «Gett». Наблюдается рост расходов, связанных с активной экспансией в новые города и укрепление позиций в регионах присутствия, а также связанных с динамикой к снижению продолжительностью поездок при сохранении средней стоимости километра поездки. Интеграция сторонних сервисов в бизнес-модель видится эффективным средством получения дополнительного дохода. В связи с этим, отделом по развитию компании была составлена матрица сторонних сервисов, предлагаемых «Gett» по всему миру (рисунок 4).

Данная стратегия активной экспансии и интеграции сторонних сервисов в бизнес-модель компании позволили достичь совокупного среднего темпа роста (CAGR) выручки с 2013 по 2017 год 146,11\%. Данная политика позволила компании значительно расширить регионы присутствия. Так, в 2016 году компания «Gett» присутствовала лишь в 7 из 10 крупнейших городов. На текущий момент ее охват составляет более 75 городов, включая все города миллионеры $[1 ; 4$, с. 43]. Однако, данная политика приводит к значительным убытком компании с момента ее появления на российском рынке, а по итогам 2017 года чистый убыток составил практически 


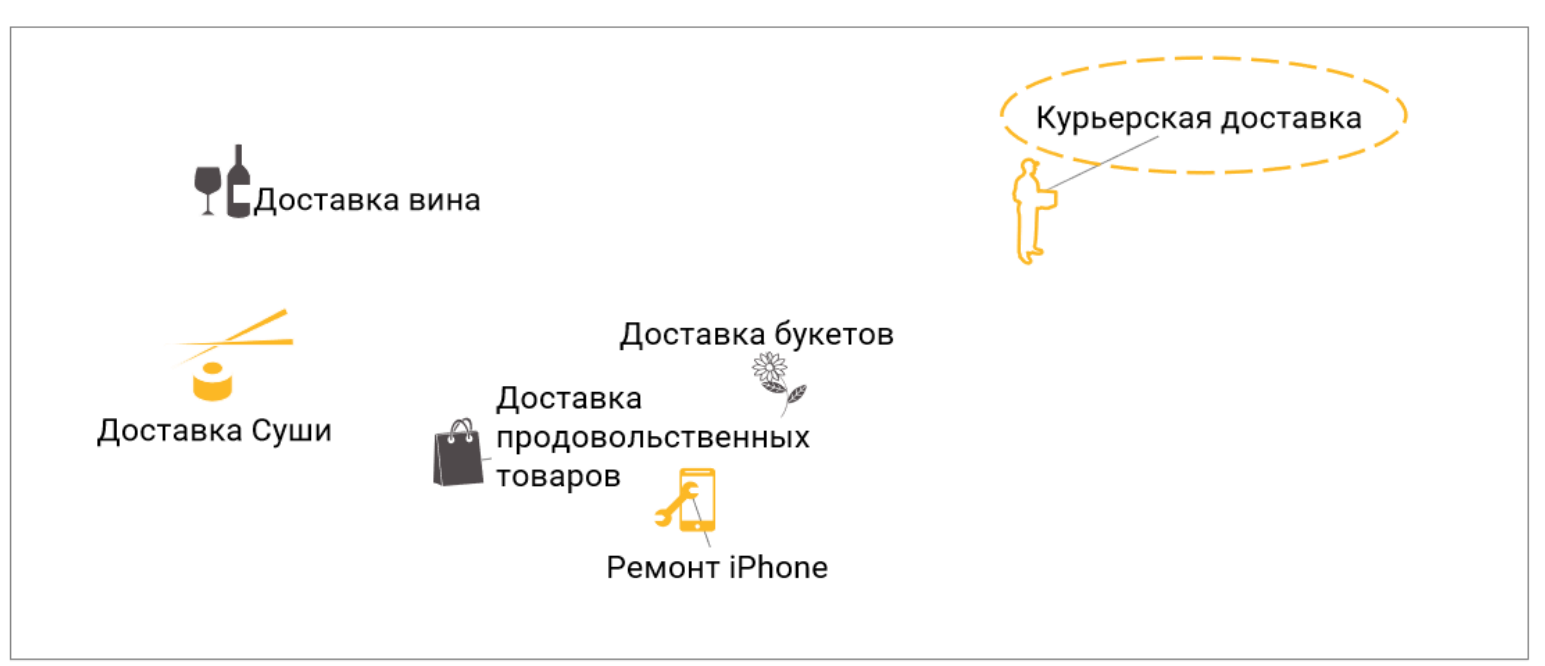

Размер рынка

Puc. 4. Характеристика сторонних сервисов в зависимости от потенциальной доходности и размера рынка, предлагаемых в странах присутствия компании «Gett» [4, с. 49]

2,5 млрд. рублей [2]. При этом следует отметить, что подобная ситуация наблюдается и с компанией «Яндекс» из-за стратегии экстенсивного роста и давления на предложение, так, в 2017 году чистый убыток агрегатора такси составил 5,76 млрд. рублей [2]. Наблюдается определенная трансформация бизнес-модели компании, что вызвано поглощением основным конкурентом компании «Uber» и использованием сильных сторон обоих агрегаторов в объединенной компании. По оценкам экспертов объединенная компания сможет обрабатывать до 80\% всех заказов онлайн уже к 2021 году [5, с. 26]. «Яндекс такси» доминирует также и на рынке сопутствующих услуг, в частности, доставке еды и др. Данная трансформация наблюдается в форме некой кастомизации бизнеса в сторону расширения В2В и сопутствующих курьерских услуг. Об этом свидетельствуют заявления на сайте относительно мирового лидерства компании на рынке корпоративного такси [1], а также роста числа и объемов контрактов за последние годы с такими российскими компаниями как «ВТБ», «ВЭБ», «Сбербанк» и др. [2]. Кастомизация бизнеса во многом обусловлена и тем, что, по оценкам компании, организация «бизнес» и «вип» перевозок, а также курьерская доставка писем и документов для корпоративных клиентов, являются наиболее доходными, что особенно актуально в сложившейся на рынке ситуации [4, с. 25, 52].

В целом, проведенный анализ свидетельствует о переходе рынка такси России в стадию «зрелости» жизненного цикла, ввиду высокой конкуренции и крупных поглощений с целью консолидации бизнеса в последнее время, к которым следует отнести слияние «RuTaxi» и «Fasten», а также «Яндекс. Такси» и «Uber». При этом, в скором времени, рынок такси России может стать еще более монополистическим. У ПАО «Сбербанк» имеются в совместном владении некоторые сервисы «Яндекса», имеются основания полагать о его дальнейшем вхождении в капитал «Яндекса» и получении полного контроля над компанией [8]. Также ПАО «Сбербанк» в конце 2016 года предоставил «Gett» венчурный кредит на \$100 млн. с получением варрантов на акции «Gett» [9].

Подводя итог вышеизложенному, представляется возможным сделать общий вывод о том, что представительствам иностранных компаний на рынке такси России на примере компании «Gett» приходится функционировать во многом на тех же конкурентных условиях, что и национальным компаниям. На отечественном рынке такси наблюдается переход к стадии «зрелости», поэтому компании вынуждены участвовать в конкурентной борьбе, заимствовать сильные стороны новейших бизнес-моделей и подстраивать глобальные модели под конкретный регион присутствия и условия работы, интегрируя в них сопутствующие сервисы для извлечения дополнительных доходов и укрепления позиций на рынке. 


\section{Библиографический список}

1. Официальный сайт компании «Gett». [Электронный ресурc] // URL: https://gett.com/

2. Система профессионального анализа рынков и компаний «СПАРК». [Электронный pecypc] // URL: http:// www.spark-interfax.ru/

3. P3 Study Text Business Analysis ACCA. - Berkshire: Emile Woolf Publishing Limited, 2010. - 515 p.

4. Gett. Разработка стратегии экспансии на российском рынке // McKinsey Business Diving. [Электронный ресурс] // URL: http://business-diving.ru/

5. Исследование рынка такси // Аналитический центр при Правительстве Российской Федерации, 2018. [Электронный ресурс] // URL: http://ac.gov.ru/files/content/15801/issledovanie-taksi-2018-pdf.pdf

6. Официальный сайт компании «Яндекс». [Электронный ресурс] // URL: https://yandex.ru/

7. Официальный сайт компании «Uber». [Электронный ресурс] // URL: https://www.uber.com/

8. ДербиловаЕ. Сбербанк можетстатькрупнымакционером «Яндекса»/Е.Дербилова,К.Болецкая,П.Кантышев// Ведомости. 2018. [Электронный ресурс] // URL: https:/www.vedomosti.ru/finance/articles/2018/10/18/784055sberbank

9. Балашова А. Приехали: Gett и Сбербанк раскрыли условия сотрудничества / [А. Балашова и др.] // РБК. 2017. [Электронный ресурс] // URL: https://www.rbc.ru/technology_and_media/03/05/2017/5900c4e69a7947d9098230 $3 f$

Поступила в редакцию 23.02.2019 